\title{
DISTRIBUTION AND TROPHIC ASSOCIATIONS OF ANT GENUS MONOMORIUM MAYR, 1855 (HYMENOPTERA: FORMICIDAE: MYRMICINAE) WITH APHIDS IN POTHWAR REGION OF PAKISTAN
}

\author{
M. T. Rasheed ${ }^{1}$, I. Bodlah ${ }^{1 *}$, A. Gull-e-Fareen ${ }^{1,2}$, H. Ali $^{3}$, M. A. Bodlah ${ }^{4}$ and M. U. Raja ${ }^{5}$ \\ ${ }^{1}$ Insect Biodiversity and Conservation Group, Department of Entomology, Pir Mehr Ali Shah Arid Agriculture \\ University, Rawalpindi, Pakistan \\ ${ }^{2}$ Department of Environmental Sciences, Pir Mehr Ali Shah Arid Agriculture University, Rawalpindi, Pakistan \\ ${ }^{3}$ Department of Entomology, University of Agriculture Faisalabad, Sub Campus Depalpur,Okara, Pakistan \\ ${ }^{4}$ Fareed Biodiversity and Conservation Centre, Department of Agricultural Engineering, Khwaja Fareed University of \\ Engineering and Information Technology, Rahim Yar Khan, Punjab, Pakistan \\ ${ }^{5}$ Department of Plant Pathology, Pir Mehr Ali Shah Arid Agriculture University, Rawalpindi, Pakistan \\ ${ }^{*}$ Corresponding author Email: imranbodlah@gmail.com
}

\begin{abstract}
Two species of genus Monomorium Mayr, 1855 namely Monomorium indicum Forel, 1902 and Monomorium sagei Forel, 1902 have been recorded for the first time from Pothwar region of Pakistan. Currently a total of five species of this genus have been documented from Pakistan. Conservation status of two newly recorded species has also been discussed. Both species have been described here using Bingham (1903). Morphological characters of prosoma, mesosoma and metasoma were used for the identification of the species. Description has been supported with micrographs of identification characters, morphometric, world distribution and GPS coordinates of Pakistan. Trophic associations of both species with aphid partners are also reported for the first time from Pakistan. M. indicum was found to be associated with 2 aphid species namely, Aphis gossypii Glover, 1877 and Aphis fabae Scopoli, 1763 while M. sagei lived in associations with Greenidea (Trichosiphum) psidii van der Goot, 1917, Aphis gossypii, A. fabae and A. fabae solanella Theobald, 1914.
\end{abstract}

Key words: Monomorium, Myrmicinae, Aphid associations, Pothwar, Pakistan.

https://doi.org/10.36899/JAPS.2020.2.0033

Published online March 02, 2020

\section{INTRODUCTION}

Genus Monomorium was first described by Mayr in 1855. Monomorium is considered as diverse and taxonomically the most difficult ant genus in the subfamily Myrmicinae, having 384 reported species and subspecies throughout the world (Antweb, 2019). Monomorium ants mostly occur in Old world, tropics, and temperate zones (Brown, 2000).This genus contains world's most widely distributed and successfully established tramp-species, sharing terrestrial habitats and microhabitats. Species of this genus are generalistic in feeding behaviour, more rarely granivorous and several species have been reported as lestobiotic or parasitic (Ettershank, 1966; Bolton, 1987).These ants prefers nesting in leaf litter, in the soil, under stone and in rotten wood (Collingwood, 1985; Collingwood and Agosti, 1996; Aldawood and Sharaf, 2011).

Members of this genus can be classified on the basis of following characters: workers monomorphic to polymorphic; 3-5 teeth at mandibles which decrease in size from anterior to posterior margin; distinct median clypeal seta; clypeus raised medially; antennae 10-12 segmented (mostly 12) with 3 segmented club; propodeal dorsum not spinose; petiole pedunculated anteriorly (Bolton, 1987; Bingham, 1903).

Various scientists have done a lot of work on this genus regarding revision and exploration of these ants like; Afrotropical region (Bolton, 1987), Australian and Malagasy region (Heterick, 2001, 2006), North America (DuBois, 1986), Neotropical region (Fernández, 2007) and for Saudi Arabia (Collingwood, 1985; Collingwood and Agosti, 1996). According to Bolton (2018) this genus is native to Afrotropical, Australasia, Indomalaya, Malagasy, Nearctic, Neotropical, Oceania and Palearctic bioregions. Forty three species belonging to genus Monomorium have been reported from Australia (Heterick, 2001; Heterick, 2003), forty species described from Saudi Arabia (Collingwood and Agosti, 1996; Sharaf et al., 2018), four species from Sri Lanka (Antweb, 2019), eight species from Afghanistan (Pisarski, 1970), nineteen species from Iran (Paknia et al., 2010) and twenty species have been reported from India (Bharti et al., 2016; Bolton, 2018). However in Pakistan, ants have been poorly studied. A limited work on ants in Pakistan includes new distributional records, new country records of ants, their associations with sucking insects 
etc. (Umair et al., 2012; Bodlah et al., 2016; Bodlah et al., 2017a, b; Rasheed et al., 2018; Bodlah et al., 2019 and Rasheed et al., 2019). As a result of our surveys during 2015-17, two species of this genus along with their association with aphids are reported for the first time from Pothwar region of Pakistan.

\section{MATERIALS AND METHODS}

Members of Genus Monomorium were collected from Pothwar during 2015-17. Specimens were collected with the help of mouth aspirator. Collected specimens were killed using potassium cyanide. A few killed individuals were preserved in $75 \%$ ethanol in glass vials; others were mounted on small triangular cards. Ant specimens were also collected from different aphid infested plants. Aphids were also collected and preserved in $75 \%$ ethanol. Taxonomic treatment was performed with the help of Labomed CZM6 microscope with the help of Bingham (1903) and Sharaf et al. (2017). Morphometric analysis was conducted by stage microscope. Micrographs were prepared using Labomed CZM6 microscope attached with digital camera (Amscope 18 megapixels, model number MU1803). Images were cleaned using Adobe Photoshop CS6 software. Ant specimens were identified up to species level using keys by Bingham (1903) while aphids were identified using keys by Blackman and Eastop (1984). Identified species were tagged with name, date of collection, habitat and coordinates of collection sites. After identification, species were deposited in the Department of Entomology, Pir Mehr Ali Shah Arid Agriculture University Rawalpindi, Pakistan. Description method, morphometric treatment and indices follow Bolton (1987), Sharaf et al. (2017). They are as given below.

TL: Total length; maximum length of body from mandibular apex to gaster dorsally

HW: Head width; Head width including eyes in full face view

HL: Head length; Head length (Excluding mandible)

SL: Scape length; entire scape length

EL: Eye length; maximum length of eyes

EW: Eye width; eye width in oblique view

WB: Weber's length; Thorax length in lateral view

PRW: Prothorax width; maximum broader part of pronotum

PL: Petiole length; length of petiole laterally

PH: Petiole height; in lateral view maximum node height

PW: Petiole width; in dorsal view maximum petiolar width

CI: Cephalic index $=\mathrm{HW} / \mathrm{HL} \times 100$

OI: Ocular index $=\mathrm{EL} / \mathrm{HW} \times 100$

SI: Scape index $=\mathrm{SL} / \mathrm{HW} \times 100$

LPI: Lateral petiole index $=\mathrm{PH} / \mathrm{PL} \times 100$

\section{RESULTS AND DISCUSSION}

\section{Monomorium indicum Forel, 1902 (Figs. 1-7)}

Description (worker): Head in full-face view distinctly longer than broad with nearly parallel sides and little broader anterior margin; median clypeal portion smooth and shining without carina, anterior clypeal margin feebly emarginated; antennae 12- segmented, terminal funicular segment large, twice longer than two preceding segments, scape short hardly crossing beyond the top of head (Fig. 4); eyes oval, small, more in length than width, placed at middle of head in oblique view. Mandibles shining and longitudinally striated. Mesosoma in profile view with a feebly convex pro-mesonotal dorsum, well developed metanotal grove (Fig. 6), propodeal spiracle small in lateral view. Petiole more in length than width, rounded posteriorly at dorsum. Postpetiole circular, attached with gaster posteriorly. Sculpture. Head, mesosoma, petiole and post petiole strongly rugose in profile view (Fig. 1, 5). Gaster smooth and shining having erect and suberect hairs (Fig. 7). Pilosity. Cephalic surface with minute pilosity, anterior clypeal margin with short and long yellowish hairs, scape and pedicle having short pilosity.Colour. Head, antennae, mesosoma, legs, petiole and post petiole dark brownish while gaster dark brownblackish.

Morphometric (Worker): $\mathbf{n}=\mathbf{5}$

\begin{tabular}{lll}
\hline Body Parts & Measurements(mm) & Indices \\
\hline HL & $0.81-0.82$ & $\mathrm{CI}=80.24-80.48$ \\
HW & $0.65-0.66$ & $\mathrm{OI}=30.76-33.33$ \\
EL & $0.2-0.22$ & $\mathrm{SI}=103.03-103.07$ \\
EW & $0.14-0.15$ & $\mathrm{LPI}=78.78-80.64$ \\
SL & $0.67-0.68$ & \\
PRW & $0.35-0.36$ & \\
WB & $0.93-0.95$ & \\
PH & $0.25-0.26$ & \\
PL & $0.31-0.33$ & \\
PW & $0.1-0.2$ & \\
\hline
\end{tabular}

Distribution: India, Hawaii, Afghanistan, United Arab Emirates (Bolton, 2018)

Material Examined: 05 ఛ , Forest area, Plant stem, Trail 6 (Islamabad) (N36²14.359'E074²30.037'), $638.55 \mathrm{~m}$.

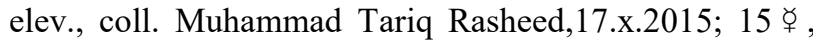
Forest area, plant stem, Kachnar Park (Islamabad)

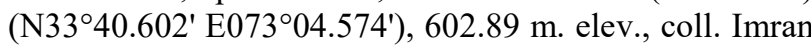
Bodlah, 20.xi.2015; 25 ఈ , Forest area, under stone, Kotli sattian (Rawalpindi) (N33 $\left.{ }^{\circ} 41.902^{\prime} \mathrm{E} 073^{\circ} 30.612^{\prime}\right)$, 1260.65 m. elev., coll. Muhammad Tariq Rasheed, 12.iv.2016; 07 ㅎ, Forest area, plant stem, Daman-e-Koh (Islamabad) (N33 $\left.{ }^{\circ} 73.95^{\prime} \mathrm{E} 073^{\circ} 10.69^{\prime}\right), 638.55 \mathrm{~m}$. elev., coll. Imran Bodlah, 02.iv.2017. 
Trophic associations with aphids: 20 ㅎ , Rawalpindi (Neela Sandh): (N3339'41.90’E73²3'3.37') 691.59 m. elev. Ammara Gull-E-Fareen, 09-iv-2016 Parthenium hysterophorus (Parthenium weed); 15 ㅎ, Rawalpindi (Charapani): (N335052.3'E73²199.1') 1204.26 m. elev. Imran Bodlah, 11-xi-2016 Parthenium hysterophorus (Parthenium weed); 23 \%, Attock (Kamrial): (N33 $\left.{ }^{\circ} 54.762^{\prime} \mathrm{E} 72^{\circ} 28.237\right) 562.66 \mathrm{~m}$. elev. Ammara GullE- Fareen, 21-xi-2016 Setaria viridis (Green Foxtail).

Comments: $M$. indicum most resembles $M$. glyciphilum but can easily be differentiated on the basis of comparison of head width. Head in front distinctly broader than posteriorly in $M$. indicum. Whereas head as broad posteriorly as in front in M. glyciphilum (Bingham, 1903).

Remarks on Ecology and on trophic associations with aphids: During surveys, specimens were observed on plant stems near water sources. Their nests were found in trees and in the soil near water sources in the forest of mountainous areas of district Rawalpindi and Islamabad. Individuals of $M$. indicum were also observed in association with sap-sucking insect viz. aphids and mealybugs for taking honey dew as food source. This ant was found in association with Aphis gossypii on Parthenium hysterophorus (Parthenium weed) and Setaria viridis (Green Foxtail) from Kamrial and on Ak plant from Charra Pani and with Aphis fabae from district Rawalpindi. Ants and aphids were present on the shoots of host plant. Aphids were sucking sap while ants were getting honey dew. M.indicum is reported for the first time in association with any aphid species from Pakistan.

Monomorium sagei Forel, 1902 (Figs. 8-14)

\section{Description (worker):}

Head. In full-face view distinctly longer than broad, feebly round at posterior margin; median clypeal portion without carinate, anterior clypeal margin smooth and feebly convex at inner margin; antennae 12- segmented with 3- segmented club (Fig. 8), scape little longer beyond the top of head; eyes smaller than $M$. indicum, placed at middle of the head. Mesosoma. In profile promesonotum forming a single convexity, metanotal grove well defined, propodeal dorsum sloping to short declivity (Fig. 11). Petiole. Longer in length than width, rounded dorsally. Postpetiole. Node massive and more rounded dorsally than petiole (Fig. 12), attached to gaster dorsally. Sculpture.In profile rugai at meso-metanotum(Fig. 13), weakly striated at metanotum dorsally, head, mandible, pro-mesonotum, petiole, Postpetiole and gaster smooth and shining. Pilosity. Cephalic surface having 3-4 erect hairs; pronotum with single seta; scattered, erect and sub erect hairs at gaster; tibiae smooth (Fig. 10 arrows), without pilosity, minute pilosity at funicular segments of antennae (Fig. 8). Colour. Head, mesosoma, legs, petiole and post petiole are pale yellowish in colour (Fig. 8, 13, 14) while gaster having blackish tint (Fig. 12).

Morphometric (Worker): $\mathbf{n}=\mathbf{5}$

\begin{tabular}{lll}
\hline Body Parts & Measurements $(\mathbf{m m})$ & Indices \\
\hline HL & $0.46-0.48$ & $\mathrm{CI}=83.33-84.78$ \\
HW & $0.39-0.40$ & $\mathrm{OI}=12.82-17$ \\
EL & $0.05-0.07$ & $\mathrm{SI}=102.56-105$ \\
EW & $0.06-0.07$ & $\mathrm{LPI}=13-70$ \\
SL & $0.4-0.42$ & \\
PRW & $0.20-0.21$ & \\
WB & $0.5-0.6$ & \\
PH & $0.013-0.14$ & \\
PL & $0.1-0.2$ & \\
PW & $0.10-0.11$ & \\
\hline
\end{tabular}

Distribution: India, Nepal, Afghanistan, China (Bolton, 2018)

Material Examined: $20 \not \dot{\varphi}$, Forest area, Tree stem, Shakarparian (Islamabad) (N334113.026'E73434.398), $491.94 \mathrm{~m}$. elev. coll. Muhammad Tariq Rasheed, 15.iv.2016; 05 ф , Forest area, plant stem, Trail 6 (Islamabad) (N36¹4.359'E74³0.037'), 638.55 m. elev., coll. Muhammad Tariq Rasheed,17.x.2015; 05 \% , Forest area, plant stem, Kachnar Park (Islamabad) (N3340.602'E7304.574'), 602.89 m. elev. coll. Imran Bodlah, 20.xi.2015; 15 ६ , Forest area, plant stem, Trail 5 (Islamabad) $\quad\left(\mathrm{N} 33^{\circ} 45.247^{\prime} \mathrm{E} 73^{\circ} 05.146^{\prime}\right), 638.55 \mathrm{~m}$. elev.coll. Imran Bodlah, 12.iv.2016; 25 ఛ , Forest area, under stone, Kotli Sattian (Rawalpindi) (N334 $\left.41.902^{\prime} \mathrm{E} 073^{\circ} 30.612^{\prime}\right), 1260.65 \mathrm{~m}$. elev. coll. Ammara Gull E Fareen, 12.iv.2016.

Trophic associations with aphids: 5 하 , Rawalpindi: (N3338.929'E7304.943) $501 \mathrm{~m}$. elev. coll. Ammara Gull -E- Fareen, 12.ii.2016. Psidium guajava (Guava); 3

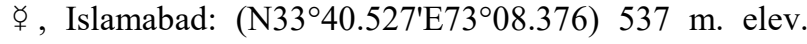
coll. Ammara Gull E Fareen, 03.iv.2016. P. guajava (Guava); 2 †, (N32³8.928'E7404.943) 499 m. elev. coll. Imran Bodlah, 27.iii.2015. Cestrum nocturnum (Night-blooming jasmine); 4 \%, Islamabad: (N33 $\left.{ }^{\circ} 40.527^{\prime} \mathrm{E}^{\circ} 2^{\circ} 08.375\right) 536 \mathrm{~m}$. elev. coll. Muhammad Tariq Rasheed, 10.iv.2016. C. nocturnum (Nightblooming jasmine); 2 \%, Islamabad: (N3340.527' $\left.\mathrm{E}^{\circ} 3^{\circ} 08.376\right) 537 \mathrm{~m}$. elev. coll. Ammara Gull E Fareen, 03.ix.2016. Solanum nigrum (Black nightshade), Spinacia oleracea (Spinach). Same plant on different coordinates.

Comments: Workers of $M$. sagei resemble more to $M$. minutum but can easily be separated in having twelve jointed antennae, scape extending beyond the top of head, mesosoma convex dorsally, cephalic surface having 3-4 erect hairs; pronotum with single seta; scattered, erect and sub erect hairs at gaster; tibiae smooth, without 
pilosity, minute pilosity at funicular segments of antennae (Bingham, 1903).

Remarks on Ecology and on trophic associations with aphids: During present studies individuals of this species were collected from nests in rotten wood, dead wood, tree bark and from the soil. They were also collected in association with mostly sucking insect like psyllids, aphids and mealy bugs etc. M. sagei was found associated with 4 aphid species namely Greenidea (Trichosiphum) psidii, Aphis gossypii, Aphis fabae solanella and Aphis fabae on Psidium guajava (Guava),Cestrum nocturnum (Night-blooming jasmine), Solanum nigrum (Black nightshade) and Spinacia oleracea (Spinach) plants from different areas of Rawalpindi and Islamabad. M. sagei is reported for the first time in association with any aphid species from Pakistan.

General Discussion: Both species were recorded from a range of habitats like in soil, near water sources, rotten wood, tree bark etc. Members of this genus have been already mentioned to be found in such microhabitats in many studies like Collingwood, 1985; Collingwood and Agosti, 1996; Aldawood and Sharaf, 2011 and Eguchi et al., 2011. Both were also found to be associated with various aphid species. Already different species of this genus have been mentioned as to be associated with various species of aphids in different parts of the world like Nielsson et al. (1971); Addicott (1979); Idechiil et al. (2007); Özdemir et al. (2008); Kataria and Kumar (2013); Shiran et al. (2013); Mortazavi et al. (2015) and Ahmad (2015).

Conservation Status of $M$. indicum and $M$. sagei: During present study $M$. indicum was found in association with Aphis gossypii on Parthenium hysterophorus (Parthenium weed) and Setaria viridis (Green Foxtail) from Kamrial and on Ak plant from Charra Pani and with Aphis fabae from district Rawalpindi. Similarly M. sagei was also observed while workers were foraging on different host plant such as Psidium guajava (Guava), Cestrum nocturnum (Nightblooming jasmine), Solanum nigrum (Black nightshade) and Spinacia oleracea (Spinach) in various localities of Rawalpindi and Islamabad. However these host plants of above mentioned insects are highly in threat of extinction due to rapid road development in village areas of district Rawalpindi and Islamabad. Similarly development of housing societies in these areas also playing a key role in the destruction of these weeds and plants by turning agriculture land into housing structure. Due to these activities population of various plants species decreasing day by day. In order to conserve these plant and its associated communities of insect, strong efforts must be made at government level. These conservation activities will ultimately conserve $M$. indicum and $M$. sagei too

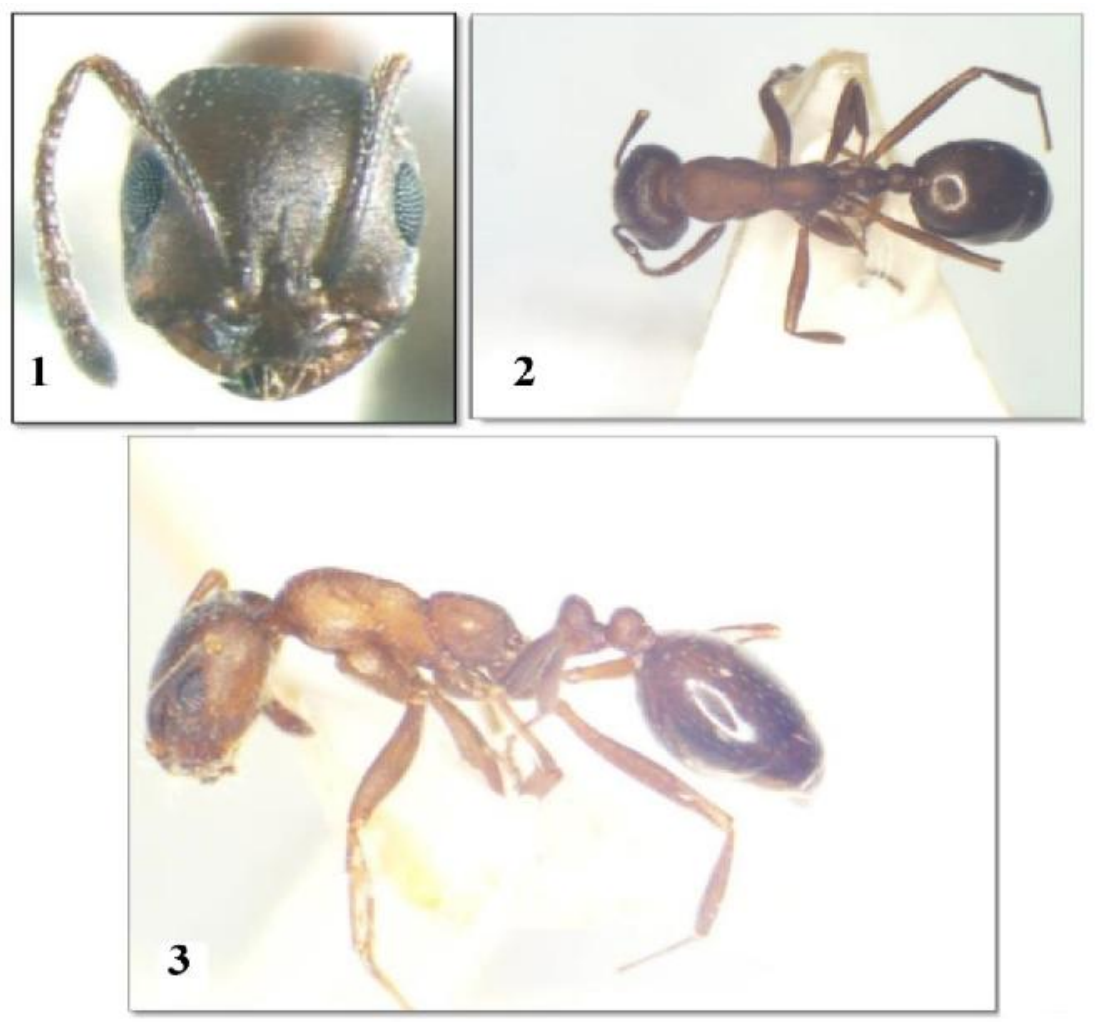

Figs. (1-3) Monomrium indicum Forel, 1902 (1) Head; ful face-view (2) Body; dorsal view(3) Body, in profile 

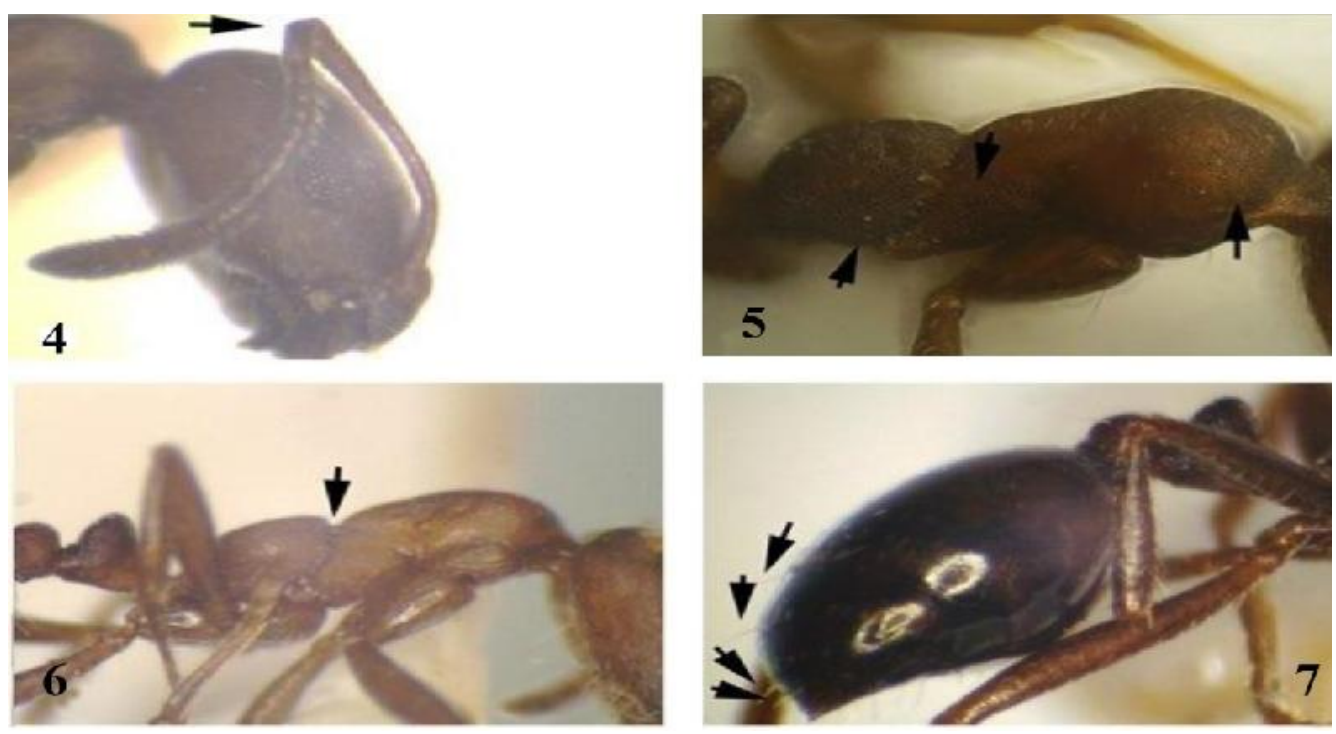

Figs. (4-7) Monomrium indicum Forel, 1902 (4) Scape short hardly crossing beyond the top of head (5) Mesosoma strongly rugose in profile view (6) Well developed metanotal grove (7) Gaster smooth and shining having erect and suberect hairs.

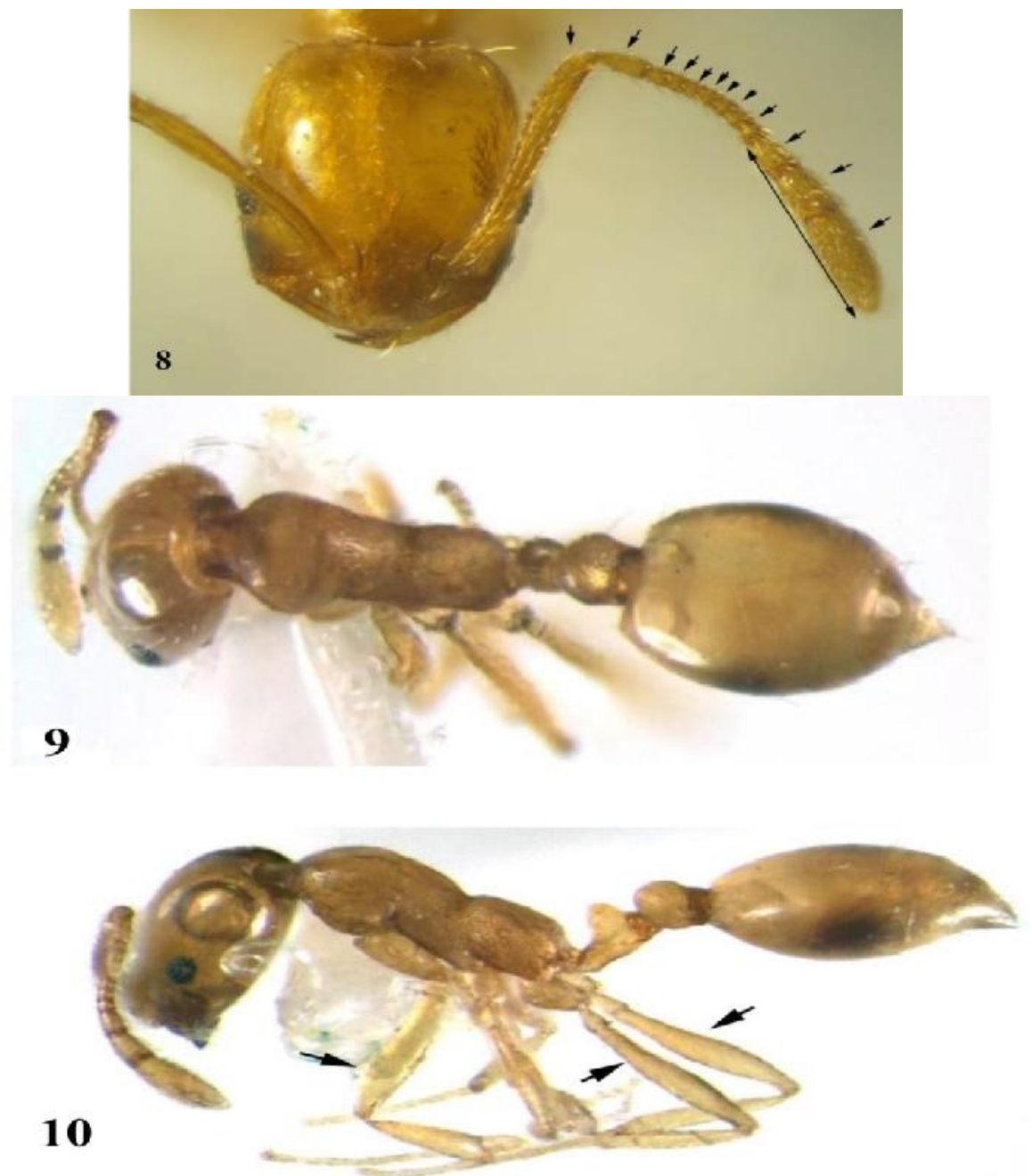

Figs. (8-10) Monomrium sagei Forel, 1902 (4) Head; ful face-view (5) Body; dorsal-view (6) Body, profile-view 


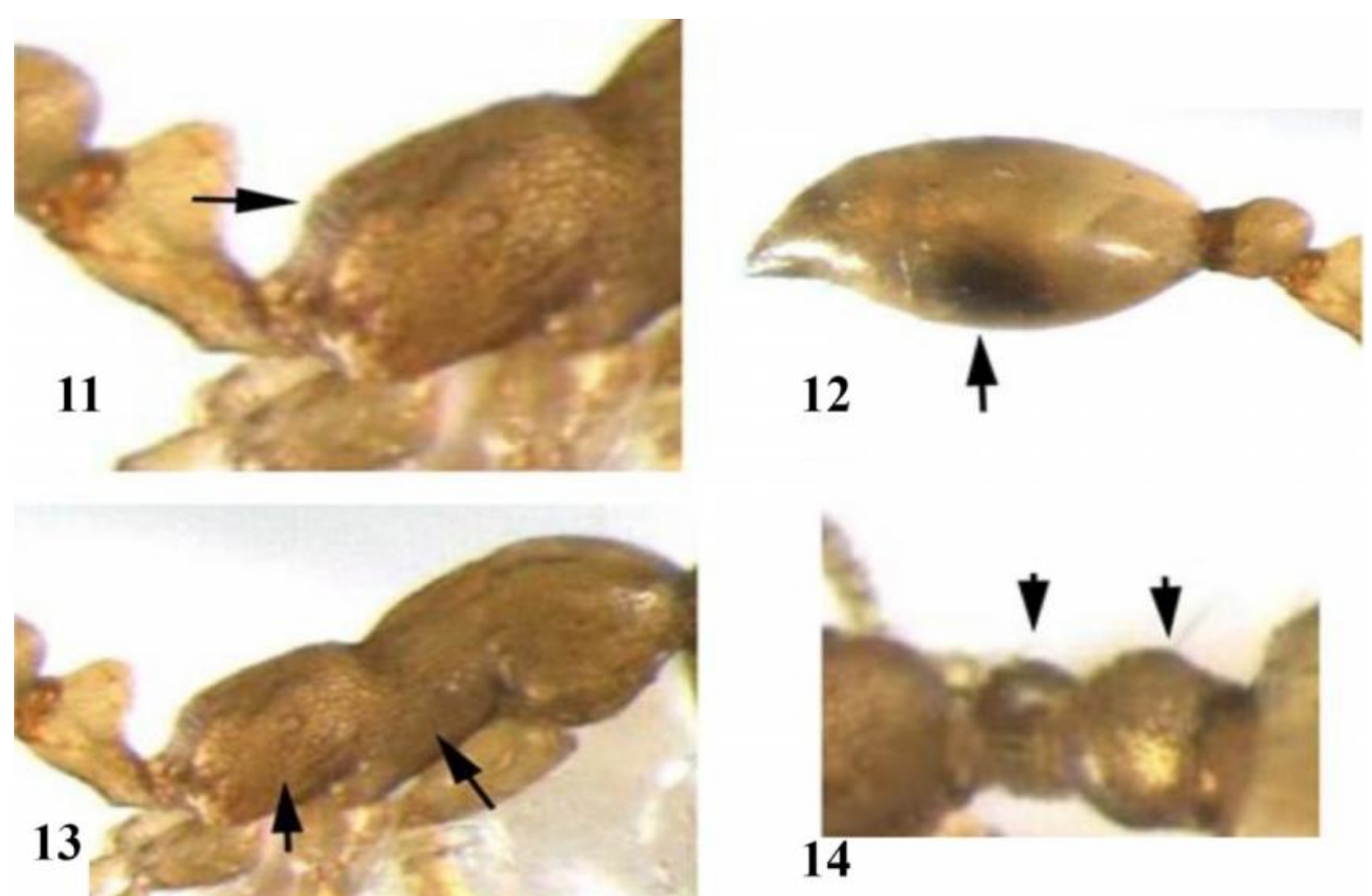

Figs. (11-14) Monomrium sagei Forel, 1902 (11) Propodeal dorsum sloping to short declivity (12)Gaster having blackish tint (13) Rugai at meso-metanotum in profile view (14) Postpetiole massive and more rounded dorsally than petiole.

Acknowledgements: This work was supported by Pakistan Science Foundation under the project PSF/NSLP/P-UAAR (313) for these studies.

\section{REFERENCES}

Addicott, J.F. (1979). A multispecies aphid-ant association: density dependence and speciesspecific effects. Can. J. Zool. 57(3): 558-569.

Aldawood, A.S., M. R.Sharaf and B. Taylor (2011). First record of the myrmicine ant genus Carebara Westwood, 1840 (Hymenoptera, Formicidae) from Saudi Arabia with description of a new species C. abuhurayri sp. n. Zookeys 92:61-69.

Ahmad, R.M.E. (2015). Study of mutualistic ants associated with Aphis craccivora (Hemiptera: Aphididae) on various host plants of family Fabaceae in Northeast Bihar (India). Eur. Sci. J. 11(18): 317-327.

AntWeb. (2019). Bolton World Catalog. https://www. antweb. org/project. do? name $=$ worldants. (Date Accessed: 12 February 2019).

Bharti, H., B. Guénard, M. Bharti, E.P Economo. (2016). An updated checklist of the ants of India with their specific distributions in Indian states (Hymenoptera, Formicidae). ZooKeys 551: 1-83
Bingham, C.T. (1903).The fauna of British India, including Ceylon and Burma.Hymenoptera.Ants and cuckoo wasps.4: $506 \mathrm{p}$.

Blackman, R.L. and V.F. Eastop (1984). Aphids on the World's Crops: An Identification Guide. John Wiley and Sons, Chickester, England.474 p.

Bodlah, I., M.T. Rasheed, A.G. Fareen, M.S. Ajmal and M.A. Bodlah (2016). First record of two new species of genus Tetraponera (Hymenoptera: Pseudomyrmecinae: Formicidae) from Pakistan. J. Entomol. Zool. Stud. 4 (4): 1028-1030.

Bodlah, I., M.A. Bodlah, M.T. Rasheed, T. Akhter. A. Aihetasham and M. Yousaf (2017a). New distributional records of psyllid, Trioza fletcheri minor Crawford, 1912 and record of its first association with two ant's species in Pothwar. Asian J. Agric. Biol.5 (1):1-6.

Bodlah, I., M.T. Rasheed andM.A. Bodlah (2017b). New distributional records of Tetraponera rufonigra (Jerdon) from Gilgit Baltistan, Pakistan. Asian J. Agric. Biol.5 (2):56-59.

Bodlah, I., M.T. Rasheed, X. Huang, A.G. Fareen, J.A. Siddiqui and M.A. Bodlah (2019). First Records of Two Species of Genus Messor Forel, 1890 (Formicidae: Myrmicinae) Along With Trophic Associations with Aphids from Pothwar Region of Pakistan. The J. Anim. Plant. Sci. 29 (4): 992997. 
Bolton, B. (1987). A review of the Solenopsis genusgroup and revision of Afrotropical Monomorium Mayr (Hymenoptera: Formicidae). Bull. Br. Mus. Nat. Hist. Zool. 54:263-452.

Bolton, B. (2017). An online catalog of the ants of the world.Available at http:// antcat.org/ (accessed on 25 May 2017).

Bolton, B. (2018). An online catalog of the ants of the world.Available at http:// antcat.org/ (accessed on 7 August 2018).

Brown, W.L. (2000). Diversity of ants. In: Agosti D, Majer J, Alonso E, Schultz TR, eds. Ants. Standard methods for measuring and monitoring biodiversity. Biological diversity hand book series, Washington, D.C.: Smithsonian Institution Press, 45-79, $280 \mathrm{p}$.

Collingwood, C.A., D. Agosti. (1996). Formicidae (Insecta: Hymenoptera) of Saudi Arabia (part 2). Fauna of Saudi Arabia. 15:300-385.

Collingwood, C.A. (1985). Hymenoptera: fam. Formicidae of Saudi Arabia. Fauna of Saudi Arabia. 7:230-302.

DuBois, M.B. (1986). A revision of the native New World species of the ant genus Monomorium (minimum-group). Kans. Univ. sci. bull.53: 65119.

Ettershank, G. (1966). A generic revision of the world Myrmicinae related to Solenopsis and Pheidologeton (Hymenoptera: Formicidae). Aust. J. Zool. 14: 73-171.

Eguchi, K., T.V. Bui and S. Yamane (2011). Generic Synopsis of the Formicidae of Vietnam (Insecta: Hymenoptera), Part I-Myrmicinae and Pseudomyrmecinae. Zootaxa, 2878, 1-61.

Fernández, F. (2007).Two new species of South American Monomorium Mayr with taxonomic notes on the genus. Mem. Am. Entomol. Inst. 80: $128-145$.

Heterick, B.E. (2001). Revision of the Australian ants of the genus Monomorium (Hymenoptera: Formicidae). Invertebr. Syst. 15:353-459.

Heterick, B.E. (2003). Two new Australian Monomorium Mayr (Hymenoptera: Formicidae), including a highly distinctive species. Aust. J. Entomol. 42: 249-253.

Heterick, B.E. (2006). A revision of the Malagasy ants belonging to genus Monomorium Mayr, 1855 (Hymenoptera: Formicidae). Proc. Calif. Acad. Sci. (4), 57:69-202.

Idechiil, O., R. Miller, K. Pike and L. Hansen. (2007). Aphids (Hemiptera: Aphididae), ants (Hymenoptera: Formicidae) and associated flora of Palau with comparisons to other Pacific Islands. Micronesica. 39(2): 141-170.

Kataria, R. and D. Kumar. (2013). On the Aphidâe "ant association and its relationship with various host plants in the Agro ecosystems of Vadodara, Gujarat, India. Halteres. 4: 25-32.

Mortazavi, Z.S., M. Sadeghi, N. Aktac, L. Depa and L. Fekrat. (2015). Ants (Hymenoptera: Formicidae) and their aphid partners (Homoptera: Aphididae) in Mashhad region, RazaviKhorasan Province, with new records of aphids and ant species for fauna of Iran. Halteres. 6: 4-12.

Nielsson, R.S.A., A.P. Bhatkar and H.A. Denmark. (1971). A preliminary list of ants associated with aphids in Florida. Florida Entomol. 54: 245-248.

Özdemir, I., N. Aktac, S. Toros, N. Kilincer and M.O. Gurkan. (2008). Investigations of the associated between aphids and ants on wild plants in Ankara province (Turkey). Mun. Ent. Zool. 3(2): 606-613.

Paknia, O., A. Radchenko and M. Pfeiffer. (2010). New records of ants (Hymenoptera: Formicidae) from Iran. Asian Myrmecol. 3, 29-38.

Pisarski, B. (1970). BeiträgezurKenntnis der Fauna Afghanistans. (Sammelergebnisse von O. Jakes 1963-64, D. Povolny 1965, D. Povolny\& Fr. Tenora 1966, J. Simek 1965-66, D. Povolny, J. Gaisler, Z. Sebek\& Fr. Tenora 1967). Formicidae, Hym. Cas. Morav. Mus. Brne 54. Su Suppl. 305-326.

Rasheed, M.T., I.Bodlah, A.G Fareen and X. Huang. (2018). First record of Leptogenys hysterica Forel, 1900 (Hymenoptera, Formicidae, Ponerinae) from Pakistan. J. Threat. Taxa. 10(15): 13032-13036

Rasheed, M. T., I.Bodlah, A.G. Fareen, A.A. Wachkoo, X. Huang, and S.A. Akbar (2019). A Checklist of Ants (Hymenoptera: Formicidae) in Pakistan. Sociobiology, 66(3), 426-439.

Shiran, E., M.S.Mossadegh and M.Esfandiari. (2013). Mutualistic ants (Hymenoptera: Formicidae) associated with aphids in central and southwestern parts of Iran. J. Crop Protec. 2(1):1-12.

Sharaf, M. R, B.L. Fisher, C.A. Collingwood and S.A. Aldawood. (2017). Ant fauna (Hymenoptera: Formicidae) of the Socotra Archipelago (Yemen): zoogeography, distribution and description of a new species. J. Nat. Hist. 51(56):317-378

Sharaf, M., M. Al.D. Hathal, S.A. Aldawood and F.H. Garcia. (2018). Ants of the Monomorium monomorium species-group (Hymenoptera: Formicidae) in the Arabian Peninsula with description of a new species from southwestern Saudi Arabia. Peer J 6:e4277.

Umair, M., A. Zia, M. Naeem and M.T. Chaudhry (2012) Species composition of ants (Hymenoptera: Formicidae) in Pothwar plateau of Punjab province, Pakistan J. Zool. (44): 699-705. 